\title{
PERENCANAAN SISTEM PENYALURAN AIR BUANGAN PADA KOMPLEK PERUM AHAN GRAND SUKATI KECAMATAN SUNGAI KAKAP KABUPATEN KUBU RAYA
}

\author{
Dewi Larasati ${ }^{1}$, Johnny, MTS $^{2}$, Yulisa Fitrianingsih ${ }^{1}$ \\ ${ }^{1}$ Program Studi Teknik Lingkungan, Fakultas Teknik, Universitas Tanjungpura, Pontianak \\ ${ }^{2}$ Program Studi Teknik Sipil, Fakultas Teknik, Universitas Tanjungpura, Pontianak \\ Email : dewilarast06@gmail.com
}

\begin{abstract}
ABSTRAK
Berkembangnya pemukiman mengakibatkan terjadinya perubahan tata guna lahan, yang sebelumnya lahan terbuka hijau menjadi lahan kegiatan pembangunan pemukiman (Grand Sukati). Agar buangan akibat curah hujan dan buangan air limbah tidak mencemari lingkungan dan lahan pertanian yang ada di lingkungan komplek perumahan Grand Sukati diperlukan perencanaan sistem penyaluran air buangan akibat curah hujan dan buangan air limbah. Dalam perencanaan saluran buangan ini memperhitungkan letak saluran drainase di kawasan pemukiman ini seperti saluran primer dan sekunder. Tahapan perencanaan drainase air hujan meliputi analisis hidrologi yaitu analisis periode ulang hujan, analisis curah hujan rencana, analisis intensitas curah hujan, analisis waktu konsentrasi, analisis koefisien limpasan permukaan, dan analisis debit puncak limpasan serta analisis hidrolika yaitu analisis kecepatan dalam saluran, menentukan dimensi penampang hidrolis saluran dengan menggunakan rumus Manning. Untuk buangan air limbah dihitung berdasarkan jumlah perumahan dan fasilitas umum sehingga jumlah perumahan akan berkurang akibat penggunan lahan untuk lokasi kolektor dan IPAL. Tahapan perencanaan sistem perpipaan air limbah meliputi analisis debit air limbah rumah tangga perhari yang dipakai dalam perencanaan dimensi pipa air limbah. Debit rencana drainase air hujan pada perencanaan ini berkisar antara $0,03 \mathrm{~m}^{3} /$ detik sampai $2,23 \mathrm{~m}^{3} /$ detik. Terdapat 47 saluran dengan periode ulang 10 tahun. Saluran drainase yang direncanakan dengan sistem terbuka secara gravitasi menggunakan penampang melintang segiempat dengan dimensi saluran primer untuk lebar saluran sebesar 1,50 $\mathrm{m}$ dan kedalaman saluran sebesar 0,75 $\mathrm{m}$ serta saluran sekunder untuk untuk lebar saluran sebesar 0,74 $\mathrm{m}$ dan kedalaman sebesar 0,37 $\mathrm{m}$. Untuk buangan air limbah debit rencana berkisar antara $0,00002 \mathrm{~m}^{3} /$ detik dan $0,02 \mathrm{~m}^{3} /$ detik. Saluran air limbah direncanakan dengan sistem perpipaan secara gravitasi dan pompa dengan bahan pipa pvc menggunakan pipa berdiameter 4" untuk pipa persil, pipa berdiameter 6" untuk pipa servis, pipa berdiameter 8" untuk pipa lateral, pipa berdiameter 8 " untuk pipa induk.
\end{abstract}

Kata kunci: Air limbah, curah hujan, debit rencana, dimensi, limpasan

\begin{abstract}
The development of the settlement led to changes in land use, which was previously open land into green land settlement development activities (Grand Sukati). To exile due to rainfall and waste water effluents do not pollute the environment and agricultural land in the neighborhood of detached house planning system required Grand Sukati channeling wastewater due to rainfall and wastewater effluents. In planning this takes into account the position of the exhaust channels channel drainage in this area such as the primary and secondary channels. Rain water drainage planning stages include analysis of the hydrologic analysis of repeated periods of rain, rainfall analysis plans, analysis of the intensity of rainfall, the analysis time of concentration, analysis of surface runoff coefficient, and the peak runoff and discharge analysis analysis of the hydraulics i.e. speed channel analysis, determine the dimensions of the cross-section of the channel using the formula hidrolis Manning. For wastewater effluents were calculated based on the amount of housing and public facilities so that the amount of housing will be reduced due to the use of land for the location of the collector and the IPAL. The planning phase of the waste water piping systems including analysis of household waste water discharge per day used in the planning of the waste water pipe dimensions. Rain water drainage plan Debit on this planning ranged between $0,03 \mathrm{~m} 3 / \mathrm{s}$ to 2,23 m3/s. There are 47 channels repeated with a period of 10 years. Drainage channels are planned with an open system for gravity using horizontal rectangles with the dimensions of the cross-section line primer to the width of the channel of $1.50 \mathrm{~m}$ and a depth of $0.75 \mathrm{~m}$ and the channel the channel width to channel secondary to $0,74 \mathrm{~m}$ and depth of $0,37 \mathrm{~m}$. For wastewater effluents discharge plans ranged from $0,00002 \mathrm{m3} / \mathrm{s}$ and $0,02 \mathrm{m3} / \mathrm{s}$. Waste water channels are planned with the piping systems are gravity and pump with PVC pipe using a pipes with a diameter of 4 " to pipe diameters pipe persil, 6 " to pipe diameter services 8 " for lateral pipe, pipe diameter 8 " to mains pipes.
\end{abstract}

Keywords : dimensions, discharge plan, rainfall, runoff, waste water 


\section{Pendahuluan}

Kawasan perumahan Grand Sukati berada di Kecamatan Sungai Kakap, Kabupaten Kubu Raya. Perumahan Grand Sukati merupakan salah satu perumahan besar di Kubu Raya. Perumahan Grand Sukati ini memiliki luas area \pm 15 ha, terdiri dari beberapa kompleks perumahan, area komersial, area rekreasi, dan sebagainya. Agar memenuhi standar bangunan yang berwawasan lingkungan yang sehat, aman, dan terhindar dari banjir diperlukan perencanaan suatu sistem penyaluran air buangan di pemukiman ini.

Menurut UU No. 28 tahun 2008 tentang bangunan kesehatan, bangunan gedung (perumahan) membutuhkan sistem sanitasi. Sistem sanitasi yang dimaksud merupakan kebutuhan sanitasi yang harus tersedia di dalam atau di luar gedung untuk memenuhi kebutuhan air bersih, pembuangan air limbah, kotoran sampah serta penyaluran air hujan.

Berdasarkan uraian tersebut maka perlu adanya suatu sistem saluran air buangan yaitu drainase pemukiman bebas dari genangan air dan bahaya banjir, serta perencanaan sistem perpipaan untuk air limbah pada Perumahan Grand Sukati yang nantinya akan dibuang ke badan air/sungai.

\section{Metodologi}

Data yang digunakan dalam perencanaan ini adalah data primer yang meliputi dokumentasi dilapangan untuk mengetahui kondisi existing wilayah Grand sukati dan data sekunder yang meliputi data curah hujan 10 tahun dari stasiun PTK-11 Pontianak serta peta-peta seperti peta topografi, peta blok perumahan dan data letak geografis dan administratif. Dalam perencanaan ini terbagi menjadi 2 bagian yaitu perencanaan drainase dan perencanaan saluran air limbah. Tahapan perencanaan drainase air hujan meliputi analisis hidrologi yaitu analisis periode ulang hujan, analisis curah hujan rencana, analisis intensitas curah hujan, analisis waktu konsentrasi, analisis koefisien limpasan permukaan, dan analisis debit puncak limpasan serta analisis hidrolika yaitu analisis kecepatan dalam saluran, menentukan dimensi penampang hidrolis saluran dengan menggunakan rumus manning. Untuk buangan air limbah dihitung berdasarkan jumlah perumahan dan fasilitas umum sehingga jumlah perumahan akan berkurang akibat penggunan lahan untuk lokasi kolektor dan IPAL. Tahapan perencanaan sistem perpipaan air limbah meliputi analisis debit air limbah rumah tangga perhari yang dipakai dalam perencanaan dimensi pipa air limbah.

Berdasarkan sumber data yang diperoleh, data yang digunakan dalam penelitian ini terbagi dua jenis, yaitu data primer dan data sekunder.

a. Data Primer

Data primer dalam penelitian ini adalah:

- Dokumentasi untuk kondisi existing wilayah Grand sukati

b. Data Sekunder

Data sekunder dalam penelitian ini adalah:

- Peta topografi untuk Informasi arah aliran saluran di lokasi perencanaan dan perhitungan perencanaan

- Letak geografis dan administratif ubtuk gambaran umum lokasi perencanaan

- Curah hujan Stasiun M eteorologi Supadio, Pontianak analisis kapasitas saluran

\section{Hasil dan Pembahasan}

A. Perencanaan Saluran Drainase

Pengolahan data curah hujan harian maksimum dihitung dengan menggunakan metode rasional yang bertujuan untuk mendapatkan parameter statistik dan pemilihan metode distribusi yang sesuai. Data curah hujan harian maksimum yang telah diolah dapat dilihat pada Tabel 1 berikut ini :

Tabel 1 Data Curah Hujan Satu Harian Maksimum ( $\mathrm{mm} /$ hari) Stasiun M eteorologi Supadio Pontianak Tahun 2002-2011

\begin{tabular}{|c|c|c|}
\hline No & Tahun & Maks (mm) \\
\hline 1 & 2002 & 25,62 \\
2 & 2003 & 24,55 \\
3 & 2004 & 22,72 \\
4 & 2005 & 24,11 \\
\hline
\end{tabular}


Tabel 1 Data Curah Hujan Satu Harian Maksimum (mm/hari) Stasiun M eteorologi Supadio Pontianak Tahun 2002-2011 (lanjutan)

\begin{tabular}{|c|c|c|}
\hline No & Tahun & Maks (mm) \\
\hline 5 & 2006 & 24.67 \\
6 & 2007 & 24.61 \\
7 & 2008 & 23.55 \\
8 & 2009 & 33.28 \\
9 & 2010 & 21.18 \\
10 & 2011 & 20.83 \\
\hline
\end{tabular}

Setelah semua data curah hujan harian maksimum didapatkan, maka langkah selanjutnya menentukan metode distribusi frekuensi dilakukan dengan cara menghitung nilai koefisien skewness (Cs), koefisien kurtosis (Ck), dan koefisien variasi (Cv) dari data curah hujan satu harian maksimum. Lalu dibandingkan dengan beberapa metode distribusi normal, distribusi log normal, distribusi gumbel, dan distribusi log pearson type III sehingga nilai perhitungannya cocok atau mendekati.

Dari hasil analisis perhitungan nilai koefisien $\mathrm{Cs}, \mathrm{Ck}$, dan $\mathrm{Cv}$ yang telah peroleh kemudian dibandingkan dengan nilai Cs, Ck, dan Cv dari masing-masing metode distribusi yang ada. Berikut merupakan hasil hasil perhitungan uji statistik dengan ketentuan yang berlaku untuk masing-masing metode yang diuji disajikan pada tabel Tabel 2 berikut ini:

Tabel 2 Perbandingan Hasil Perhitungan Uji Statistik dengan Ketentuan yang Berlaku untuk Masingmasing M etode yang Diuji

\begin{tabular}{|c|c|c|c|c|}
\hline Metode & Cs & Ck & Cv & Keterangan \\
\hline Perhitungan & 1,9677 & 0,8728 & 0,14 & \\
\hline Gumbell & 5,402 & 1,139 & 0,14 & \\
Log Pearson Tipe III & $>\mathbf{0}$ & $\mathbf{0 , 2 8 1}$ & $\mathbf{0 , 1 4}$ & Mendekati \\
Normal & 0 & 0 & 0,14 & \\
Log Normal & $>0$ & 0,42 & 0,14 & \\
\hline
\end{tabular}

Dari keempat metode, nilai Cs, Ck, dan Cv yang mendekati hasil perhitungan adalah metode Log pearson Type III sehingga dalam perhitungan ini metode distribusi frekuensi yang di gunakan adalah metode Log Pearson Type III.

\section{Perhitungan Curah hujan Rencana dengan Distribusi Log Pearson Type III}

Untuk mencari Curah Hujan Rencana digunakan rumus distribusi Log Pearson Type III sebagai berikut :

$\log X \operatorname{tr}=\log X+(k \cdot \log S x)$

Berdasarkan nilai Cs yang didapat adalah 1,564. Untuk menentukan nilai K periode ulang 2 tahun, 5 tahun dan 10 tahun maka di lakukan teknik interpolasi yang mana nilai Cs $=1,564$ berada diantara nilai Cs 1,4 dan 1,6 pada tabel $\mathrm{K}$ distribusi Log Pearson Tipe III. Perhitungan teknik interpolasi dapat dilihat pada Tabel 3 berikut ini:

Tabel 3 Nilai K Berdasarkan Tabel dan Interpolasi

\begin{tabular}{|c|c|c|c|c|}
\hline \multirow{2}{*}{ Cs } & \multicolumn{3}{|c|}{$\mathbf{K}$} \\
\cline { 2 - 5 } & $\mathbf{P U}_{\mathbf{2}}$ & $\mathbf{P U}_{\mathbf{5}}$ & $\mathbf{P U}_{\mathbf{1 0}}$ & Keterangan \\
\hline 1,400 & $-0,225$ & 0,705 & 1,337 & Data Log P III \\
1,564 & $-0,245$ & 0,685 & 1,332 & Interpolasi \\
1,600 & $-0,254$ & 0,675 & 1,329 & Data Log P III \\
\hline
\end{tabular}

Dengan nilai K untuk tiap-tiap periode ulang 2, 5, dan 10 tahun diantaranya $-0,245 ; 0,685$ dan 1,332 Maka didapatkan besarnya debit hujan rencana untuk berbagai periode ulang diantaranya R2 $=23,56$ $\mathrm{mm}, \mathrm{R} 5=26,57 \mathrm{~mm}$, dan R10 $=28,88 \mathrm{~mm}$ 
Setelah nilai debit hujan rencana didapat, maka Intensitas Hujan dapat dihitung. Untuk menghitung besarnya intensitas hujan terlebih dahulu menghitung waktu konsentrasi hujan dengan menggunakan rumus Kirpich, maka diperoleh waktu konsentrasi hujan $\left(\mathrm{t}_{c}\right)$ sebagai berikut :

$\mathrm{t}_{\mathrm{c}}=\left[\left(0,87 \times \mathrm{L}^{2}\right) /(1000 \times \mathrm{S})\right]^{0,385}$

Maka didapatkan tc sebesar 1,97 jam. Setelah nilai $t_{c}$ diperoleh, maka langkah selanjutnya menghitung nilai intensitas hujan (I) dengan menggunakan rumus M ononobe, sebagai berikut :

$$
\mathrm{I}=? \frac{\mathrm{R}_{24}}{24} ? ? \frac{24}{\mathrm{Tc}} ?^{2 / 3}
$$

Maka didapatkan nilai Intensitas Hujan dengan periode ulang 2, 5, dan 10 tahun masing-masing adalah $48,40 \mathrm{~mm} / \mathrm{jam} ; 54,58 \mathrm{~mm} / \mathrm{jam}$ dan $59,34 \mathrm{~mm} / \mathrm{jam}$.

\section{Perhitungan Debit Limpasan Hujan $\left(\mathbf{Q}_{\mathbf{p}}\right)$}

Debit limpasan hujan dihitung dengan menggunakan rumus sebagai berikut:

$?=0,278 . ? . ?$ ? ini :

Berikut ini adalah perhitungan debit limpasan hujan untuk Q1-Q8 dapat dilihat pada Tabel 4 berikut Tabel 4 Debit Puncak Limpasan Hujan (Qp) pada Setiap Blok Pengaliran

\begin{tabular}{|c|c|c|c|c|c|}
\hline Nama Blok & $\begin{array}{l}\text { Nama } \\
\text { Saluran }\end{array}$ & C & $\begin{array}{c}\text { I } \\
\mathrm{mm} / \mathrm{jam}\end{array}$ & A $\quad\left(\mathrm{km}^{2}\right)$ & Qp $\quad m^{3} /$ detik \\
\hline \multirow[t]{2}{*}{ A } & Q1 & 0,95 & 59,34 & 0,005 & 0,28 \\
\hline & Q2 & 0,95 & 59,34 & 0,005 & 0,28 \\
\hline \multirow[t]{6}{*}{ B } & Q3 & 0,73 & 59,34 & 0,004 & 0,19 \\
\hline & Q4 & 0,73 & 59,34 & 0,003 & 0,13 \\
\hline & Q5 & 0,73 & 59,34 & 0,003 & 0,13 \\
\hline & Q6 & 0,50 & 59,34 & 0,003 & 0,09 \\
\hline & Q7 & 0,50 & 59,34 & 0,006 & 0,17 \\
\hline & Q8 & 0,38 & 59,34 & 0,004 & 0,09 \\
\hline \multirow[t]{10}{*}{ C } & Q9 & 0,38 & 59,34 & 0,004 & 0,09 \\
\hline & Q10 & 0,50 & 59,34 & 0,006 & 0,17 \\
\hline & Q11 & 0,50 & 59,34 & 0,003 & 0,09 \\
\hline & Q12 & 0,50 & 59,34 & 0,003 & 0,09 \\
\hline & Q13 & 0,50 & 59,34 & 0,004 & 0,11 \\
\hline & Q14 & 0,50 & 59,34 & 0,003 & 0,10 \\
\hline & Q15 & 0,50 & 59,34 & 0,004 & 0,11 \\
\hline & Q16 & 0,50 & 59,34 & 0,004 & 0,11 \\
\hline & Q17 & 0,50 & 59,34 & $\mathrm{n} / \mathrm{a}$ & 0,32 \\
\hline & Q18 & 0,50 & 59,34 & $\mathrm{n} / \mathrm{a}$ & 0,36 \\
\hline \multicolumn{5}{|c|}{ SALURAN PRIM ER 1} & 2,23 \\
\hline \multirow[t]{2}{*}{$\mathrm{D}$} & Q19 & 0,60 & 59,34 & 0,002 & 0,08 \\
\hline & Q20 & 0,60 & 59,34 & 0,009 & 0,32 \\
\hline \multirow[t]{7}{*}{$E$} & Q21 & 0,50 & 59,34 & 0,003 & 0,09 \\
\hline & Q22 & 0,50 & 59,34 & 0,003 & 0,10 \\
\hline & Q23 & 0,50 & 59,34 & 0,002 & 0,07 \\
\hline & Q24 & 0,50 & 59,34 & 0,004 & 0,12 \\
\hline & Q25 & 0,50 & 59,34 & 0,001 & 0,04 \\
\hline & Q26 & 0,50 & 59,34 & 0,001 & 0,04 \\
\hline & Q27 & 0,50 & 59,34 & 0,002 & 0,06 \\
\hline \multirow[t]{2}{*}{$\mathrm{F}$} & Q28 & 0,35 & 59,34 & 0,007 & 0,14 \\
\hline & Q29 & 0,35 & 59,34 & 0,006 & 0,12 \\
\hline \multicolumn{5}{|c|}{ SALURAN PRIM ER 2} & 1,16 \\
\hline \multirow[t]{7}{*}{ G } & Q30 & 0,50 & 59,34 & 0,004 & 0,10 \\
\hline & Q31 & 0,50 & 59,34 & 0,003 & 0,40 \\
\hline & Q32 & 0,50 & 59,34 & 0,002 & 0,07 \\
\hline & Q33 & 0,50 & 59,34 & 0,002 & 0,07 \\
\hline & Q34 & 0,50 & 59,34 & 0,003 & 0,10 \\
\hline & Q35 & 0,38 & 59,34 & 0,004 & 0,08 \\
\hline & Q36 & 0,50 & 59,34 & 0,003 & 0,08 \\
\hline
\end{tabular}


Tabel 4 Debit Puncak Limpasan Hujan (Qp) pada Setiap Blok Pengaliran (lanjutan)

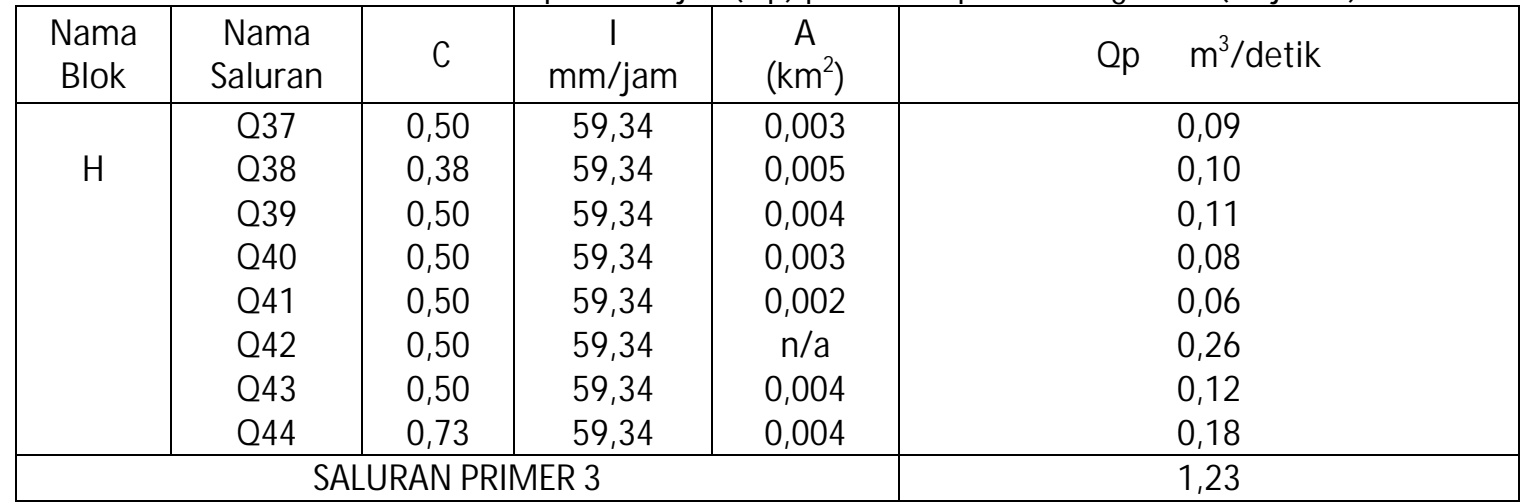

Debit limpasan dari hasil perhitungan pada tabel 4 akan digunakan untuk menghitung dimensi pada desain saluran. Debit limpasan yang terbesar diperoleh pada saluran primer I adalah 2,23 $\mathrm{m}^{3} /$ detik sedangkan debit limpasan yang lainnya berkisar antara $0,03 \mathrm{~m}^{3} /$ detik sampai $1,23 \mathrm{~m}^{3} /$ detik.

Perhitungan dimensi penampang hidrolis saluran drainase dihitung dengan menggunakan rumus Manning dan metode aljabar :

$$
\begin{aligned}
& \mathrm{Q}=\mathrm{V} \times \mathrm{A} \\
& \mathrm{Q}=? \frac{1}{\mathrm{n}} \mathrm{R}^{2 / 3} \mathrm{~S}^{1 / 2} ? \mathrm{~A}
\end{aligned}
$$

Berikut ini didapatkan dimensi tiap saluran drainase yang menggunakan penampang segiempat dengan dinding saluran beton dipoles yang dapat dilihat pada Tabel 5 berikut ini :

\begin{tabular}{|c|c|c|c|c|c|c|c|c|c|c|c|c|}
\hline $\begin{array}{l}\text { Nama } \\
\text { Blok }\end{array}$ & $\begin{array}{l}\text { Nama } \\
\text { Saluran }\end{array}$ & $n$ & $S_{0}$ & $\begin{array}{c}y \\
(m)\end{array}$ & $\begin{array}{c}\text { b } \\
\text { (m) }\end{array}$ & $\begin{array}{c}V \\
\text { (m/detik) }\end{array}$ & Ket. & $\begin{array}{c}V_{\text {izin }} \\
\text { (m/detik) }\end{array}$ & $\begin{array}{l}Q \text { desain } \\
\left(\mathrm{m}^{3} / \text { det }\right)\end{array}$ & Ket & $\begin{array}{c}\mathbf{Q} \\
\text { rencana } \\
\left(\mathrm{m}^{3} / \text { det }\right) \\
\end{array}$ & $\begin{array}{c}f \\
\text { (m) }\end{array}$ \\
\hline \multirow[t]{2}{*}{ A } & Q1 & 0,02 & 0,006 & 0,35 & 0,70 & 1,21 & $>$ & 0,46 & 0,30 & $>$ & 0,28 & 0,11 \\
\hline & Q2 & 0,02 & 0,006 & 0,35 & 0,70 & 1,21 & $>$ & 0,46 & 0,30 & $>$ & 0,28 & 0,11 \\
\hline \multirow[t]{6}{*}{ B } & Q3 & 0,02 & 0,006 & 0,30 & 0,60 & 1,09 & $>$ & 0,46 & 0,20 & $>$ & 0,19 & 0,09 \\
\hline & Q4 & 0,02 & 0,006 & 0,27 & 0,53 & 1,01 & $>$ & 0,46 & 0,14 & $>$ & 0,13 & 0,08 \\
\hline & Q5 & 0,02 & 0,006 & 0,27 & 0,53 & 1,01 & $>$ & 0,46 & 0,14 & $>$ & 0,13 & 0,08 \\
\hline & Q6 & 0,02 & 0,006 & 0,23 & 0,46 & 0,92 & $>$ & 0,46 & 0,10 & $>$ & 0,09 & 0,07 \\
\hline & Q7 & 0,02 & 0,006 & 0,29 & 0,58 & 1,07 & $>$ & 0,46 & 0,18 & $>$ & 0,17 & 0,09 \\
\hline & Q8 & 0,02 & 0,006 & 0,23 & 0,46 & 0,92 & $>$ & 0,46 & 0,10 & $>$ & 0,09 & 0,07 \\
\hline \multirow[t]{10}{*}{ C } & Q9 & 0,02 & 0,006 & 0,24 & 0,47 & 0,93 & $>$ & 0,46 & 0,10 & $>$ & 0,09 & 0,07 \\
\hline & Q10 & 0,02 & 0,006 & 0,29 & 0,58 & 1,07 & $>$ & 0,46 & 0,18 & $>$ & 0,17 & 0,09 \\
\hline & Q11 & 0,02 & 0,006 & 0,24 & 0,48 & 0,94 & $>$ & 0,46 & 0,11 & $>$ & 0,09 & 0,07 \\
\hline & Q12 & 0,02 & 0,006 & 0,24 & 0,48 & 0,94 & $>$ & 0,46 & 0,11 & $>$ & 0,09 & 0,07 \\
\hline & Q13 & 0,02 & 0,006 & 0,25 & 0,50 & 0,97 & $>$ & 0,46 & 0,12 & $>$ & 0,11 & 0,08 \\
\hline & Q14 & 0,02 & 0,006 & 0,24 & 0,48 & 0,94 & $>$ & 0,46 & 0,11 & $>$ & 0,10 & 0,07 \\
\hline & Q15 & 0,02 & 0,006 & 0,25 & 0,50 & 0,97 & $>$ & 0,46 & 0,12 & $>$ & 0,11 & 0,08 \\
\hline & Q16 & 0,02 & 0,006 & 0,25 & 0,50 & 0,97 & $>$ & 0,46 & 0,12 & $>$ & 0,11 & 0,08 \\
\hline & Q17 & 0,02 & 0,006 & 0,37 & 0,74 & 1,26 & $>$ & 0,46 & 0,34 & $>$ & 0,32 & 0,11 \\
\hline & Q18 & 0,02 & 0,006 & 0,39 & 0,77 & 1,29 & $>$ & 0,46 & 0,38 & $>$ & 0,36 & 0,12 \\
\hline \multicolumn{2}{|c|}{ SALURAN PRIMER 1} & 0,02 & 0,006 & 0,75 & 1,50 & 2,01 & $>$ & 0,46 & 2,27 & $>$ & 2,23 & 0,23 \\
\hline \multirow[t]{2}{*}{ D } & Q19 & 0,02 & 0,006 & 0,23 & 0,46 & 0,92 & $>$ & 0,46 & 0,10 & $>$ & 0,08 & 0,07 \\
\hline & Q20 & 0,02 & 0,006 & 0,37 & 0,74 & 1,26 & $>$ & 0,46 & 0,34 & $>$ & 0,32 & 0,11 \\
\hline \multirow[t]{6}{*}{ E } & Q21 & 0,02 & 0,006 & 0,24 & 0,47 & 0,93 & $>$ & 0,46 & 0,10 & $>$ & 0,09 & 0,07 \\
\hline & Q22 & 0,02 & 0,006 & 0,25 & 0,50 & 0,97 & $>$ & 0,46 & 0,12 & $>$ & 0,10 & 0,08 \\
\hline & Q23 & 0,02 & 0,006 & 0,23 & 0,45 & 0,90 & $>$ & 0,46 & 0,09 & $>$ & 0,07 & 0,07 \\
\hline & Q24 & 0,02 & 0,006 & 0,27 & 0,54 & 1,02 & $>$ & 0,46 & 0,15 & $>$ & 0,12 & 0,08 \\
\hline & Q25 & 0,02 & 0,006 & 0,20 & 0,40 & 0,83 & $>$ & 0,46 & 0,07 & $>$ & 0,04 & 0,06 \\
\hline & Q26 & 0,02 & 0,006 & 0,20 & 0,40 & 0,83 & $>$ & 0,46 & 0,07 & $>$ & 0,04 & 0,06 \\
\hline
\end{tabular}

Tabel 5. Dimensi Saluran Drainase Penampang Segiempat 
Tabel 5. Dimensi Saluran Drainase Penampang Segiempat (lanjutan)

\begin{tabular}{|c|c|c|c|c|c|c|c|c|c|c|c|c|}
\hline $\begin{array}{l}\text { Nama } \\
\text { Blok }\end{array}$ & $\begin{array}{l}\text { Nama } \\
\text { Saluran }\end{array}$ & $\mathbf{n}$ & $\mathrm{S}_{0}$ & $\begin{array}{c}y \\
\text { (m) }\end{array}$ & $\begin{array}{l}\text { b } \\
\text { (m) }\end{array}$ & $\begin{array}{c}\text { V } \\
\text { (m/detik) }\end{array}$ & Ket. & $\begin{array}{c}V_{\text {izin }} \\
\text { (m/detik) }\end{array}$ & $\begin{array}{l}Q \text { desain } \\
\left(\mathrm{m}^{3} / \text { det }\right)\end{array}$ & Ket & $\begin{array}{c}\mathbf{Q} \\
\text { rencana } \\
\left(\mathrm{m}^{3} / \mathrm{det}\right)\end{array}$ & $\begin{array}{l}F \\
\text { (m) }\end{array}$ \\
\hline \multirow{3}{*}{$\mathrm{F}$} & Q27 & 0,02 & 0,006 & 0,22 & 0,43 & 0,88 & $>$ & 0,46 & 0,08 & $>$ & 0,06 & 0,06 \\
\hline & Q28 & 0,02 & 0,006 & 0,28 & 0,56 & 1,04 & $>$ & 0,46 & 0,16 & $>$ & 0,14 & 0,08 \\
\hline & Q29 & 0,02 & 0,006 & 0,27 & 0,53 & 1,01 & $>$ & 0,46 & 0,14 & $>$ & 0,12 & 0,08 \\
\hline \multicolumn{2}{|c|}{ SALURAN PRIMER 2} & 0,02 & 0,006 & 0,59 & 1,18 & 1,72 & $>$ & 0,46 & 1,19 & $>$ & 1,16 & 0,18 \\
\hline \multirow[t]{8}{*}{ G } & Q30 & 0,02 & 0,006 & 0,25 & 0,50 & 0,97 & $>$ & 0,46 & 0,12 & $>$ & 0,10 & 0,08 \\
\hline & Q31 & 0,02 & 0,006 & 0,40 & 0,80 & 1,32 & $>$ & 0,46 & 0,42 & $>$ & 0,40 & 0,12 \\
\hline & Q32 & 0,02 & 0,006 & 0,23 & 0,45 & 0,90 & $>$ & 0,46 & 0,09 & $>$ & 0,07 & 0,07 \\
\hline & Q33 & 0,02 & 0,006 & 0,23 & 0,45 & 0,90 & $>$ & 0,46 & 0,09 & $>$ & 0,07 & 0,07 \\
\hline & Q34 & 0,02 & 0,006 & 0,25 & 0,50 & 0,97 & $>$ & 0,46 & 0,12 & $>$ & 0,10 & 0,08 \\
\hline & Q35 & 0,02 & 0,006 & 0,23 & 0,45 & 0,90 & $>$ & 0,46 & 0,09 & $>$ & 0,08 & 0,07 \\
\hline & Q36 & 0,02 & 0,006 & 0,23 & 0,45 & 0,90 & $>$ & 0,46 & 0,09 & $>$ & 0,08 & 0,07 \\
\hline & Q37 & 0,02 & 0,006 & 0,25 & 0,50 & 0,97 & $>$ & 0,46 & 0,12 & $>$ & 0,09 & 0,08 \\
\hline \multirow[t]{7}{*}{$\mathrm{H}$} & Q38 & 0,02 & 0,006 & 0,25 & 0,50 & 0,97 & $>$ & 0,46 & 0,12 & $>$ & 0,10 & 0,08 \\
\hline & Q39 & 0,02 & 0,006 & 0,27 & 0,53 & 1,01 & $>$ & 0,46 & 0,14 & $>$ & 0,11 & 0,08 \\
\hline & Q40 & 0,02 & 0,006 & 0,23 & 0,46 & 0,92 & $>$ & 0,46 & 0,10 & $>$ & 0,08 & 0,07 \\
\hline & Q41 & 0,02 & 0,006 & 0,21 & 0,42 & 0,86 & $>$ & 0,46 & 0,08 & $>$ & 0,06 & 0,06 \\
\hline & Q42 & 0,02 & 0,006 & 0,35 & 0,70 & 1,21 & $>$ & 0,46 & 0,30 & $>$ & 0,26 & 0,11 \\
\hline & Q43 & 0,02 & 0,006 & 0,27 & 0,54 & 1,02 & $>$ & 0,46 & 0,15 & $>$ & 0,12 & 0,08 \\
\hline & Q44 & 0,02 & 0,006 & 0,30 & 0,60 & 1,09 & $>$ & 0,46 & 0,20 & $>$ & 0,18 & 0,09 \\
\hline \multicolumn{2}{|c|}{ SALURAN PRIMER 3} & 0,02 & 0,006 & 0,60 & 1,20 & 1,74 & $>$ & 0,46 & 1,25 & $>$ & 1,23 & 0,18 \\
\hline
\end{tabular}

Berdasarkan tabel 5 dimensi saluran drainase diperoleh debit desain lebih besar dari debit rencana. Kecepatan yang diperoleh berada diatas kecepatan yang diizinkan yaitu 0,46 $\mathrm{m} /$ detik agar dapat mengikis sedimen (pasir halus, koloida yang mengacu pada tabel 2.7) yang berada di saluran berlapis beton. Untuk mencegah terjadinya luapan air kalau terjadi banjir yang lebih besar direncanakan tinggi jagaan 30\% dari kedalaman air.

\section{B. Perencanaan Saluran Air Limbah}

Besarnya debit air limbah yang dihasilkan mengacu pada Peraturan Gubernur Provinsi DKI Jakarta No. 122 tahun 2005. Hasil Perhitungan debit air limbah pada Komplek Perumahan Grand Sukati disajikan pada Tabel 6 berikut ini:

Tabel 6 Debit Air Limbah Perumahan Grand Sukati

\begin{tabular}{|c|c|c|c|c|c|}
\hline Bangunan & $\begin{array}{c}\text { Jumlah } \\
\text { (Unit) }\end{array}$ & $\begin{array}{c}\text { Asumsi } \\
\text { (org/ unit) }\end{array}$ & $\begin{array}{c}\text { Asumsi debit } \\
\text { air limbah (L) }\end{array}$ & $\begin{array}{c}\text { Q Air Limbah } \\
\text { (L/ hari) }\end{array}$ & $\begin{array}{c}\text { Q Air Limbah } \\
\text { (m3/ detik) }\end{array}$ \\
\hline Rumah tipe 95 & 158 & 5 & 120 & 94800 & 0,001097 \\
Rumah tipe 65 & 115 & 5 & 120 & 69000 & 0,000799 \\
Rumah tipe 45 & 159 & 5 & 120 & 95400 & 0,001104 \\
Club House & 1 & 20 & 20 & 400 & 0,000005 \\
Mushola & 1 & 15 & 10 & 150 & 0,000002 \\
TK & 1 & 50 & 25 & 1250 & 0,000014 \\
SD & 1 & 50 & 32 & 1600 & 0,000019 \\
SM P & 1 & 50 & 40 & 2000 & 0,000023 \\
Ruko & 66 & 5 & 80 & 26400 & 0,000306 \\
Kolam renang & 1 & - & - & 1680000 & 0,019444 \\
\hline & & & Total Debit & $\mathbf{1 9 7 1 0 0 0}$ & $\mathbf{0 , 0 2 2 8 1 3}$ \\
\hline
\end{tabular}

Penentuan diameter pipa yang akan digunakan untuk penyaluran air buangan ditinjau untuk mengalirkan air limbah yang cukup sesuai dengan debit limbah yang dihasilkan. Berikut ini hasil analisis perhitungan debit untuk pipa servis, pipa lateral dan pipa induk yang disajikan pada Tabel 7 berikut ini: 
Tabel 7 Perhitungan Debit Untuk Pipa Servis, Pipa Lateral Dan Pipa Induk

\begin{tabular}{|c|c|c|c|c|c|}
\hline $\begin{array}{l}\text { Nama Pipa } \\
\text { Servis }\end{array}$ & $Q$ (m3/ detik) & $\begin{array}{c}\text { Nama Pipa } \\
\text { Lateral }\end{array}$ & Q ke TPS (m3/ detik) & Nama Pipa Induk & Q Pipa TPS ke IPAL (m3/detik) \\
\hline $\mathrm{R} 1$ & 0,00031 & & & & \\
\hline R2 & 0,00031 & S1 & 0,00061 & $\mathrm{~T} 1$ & 0,00061 \\
\hline R3 & 0,00011 & & & & \\
\hline R4 & 0,00015 & $\mathrm{~S} 2$ & 0,00026 & & \\
\hline R5 & 0,00008 & & & $\mathrm{~T} 2$ & 0,00068 \\
\hline R6 & 0,00008 & S3 & 0,00017 & & \\
\hline R7 & 0,0001 & & & & \\
\hline $\mathrm{R} 8$ & 0,00016 & S4 & 0,00026 & & \\
\hline R9 & 0,00014 & & & & \\
\hline R10 & 0,00008 & S5 & 0,00023 & & \\
\hline R11 & 0,00009 & & & T3 & 0,00041 \\
\hline R12 & 0,00009 & S6 & 0,00018 & & \\
\hline R13 & 0,00009 & & & & \\
\hline R14 & 0,00009 & & & & \\
\hline R15 & 0,00013 & $\mathrm{~S} 7$ & 0,00031 & T4 & 0,00053 \\
\hline R14 & 0,00009 & & & & \\
\hline R15 & 0,00013 & S8 & 0,00022 & & \\
\hline R16 & 0,00013 & S9 & 0,00013 & & \\
\hline R17 & 0,00013 & $\mathrm{~S} 10$ & 0,00015 & & \\
\hline R18 & 0,00003 & & & T5 & 0,00053 \\
\hline R19 & 0,00007 & $\mathrm{~S} 11$ & 0,00009 & & \\
\hline R20 & 0,00015 & & & & \\
\hline R21 & 0,00001 & $\mathrm{~S} 12$ & 0,00016 & & \\
\hline R22 & 0,00013 & & & & \\
\hline R23 & 0,00009 & & & & \\
\hline \multirow[t]{2}{*}{ R24 } & 0,00009 & $\mathrm{~S} 13$ & 0,00031 & T6 & 0,00049 \\
\hline & & S14 & 0,00018 & & \\
\hline R25 & 0,00009 & & & & \\
\hline R26 & 0,00009 & S15 & 0,00018 & & \\
\hline R27 & 0,00008 & & & $\mathrm{~T} 7$ & 0,00041 \\
\hline R28 & 0,00014 & $\mathrm{~S} 16$ & 0,00023 & & \\
\hline R29 & 0,00018 & & & & \\
\hline R30 & 0,00012 & S17 & 0,00029 & & \\
\hline R31 & 0,00011 & & & T8 & 0,00053 \\
\hline R32 & 0,00008 & $\mathrm{~S} 18$ & 0,00018 & & \\
\hline R33 & 0,00005 & S19 & 0,00005 & & \\
\hline
\end{tabular}

Dimensi pipa air limbah dihitung dengan menggunakan rumus Manning. Bahan pipa yang dipakai adalah pipa PVC dengan nilai kekasaran manning dalam pipa yaitu 0,015. Diameter pipa yang digunakan untuk pipa persil 4", pipa servis sebesar 6", pipa lateral sebesar 8", dan pipa induk sebesar 8". Pemilihan diameter pipa dilakukan dengan tujuan untuk mendapatkan debit perhitungan lebih besar dari debit buangan agar pipa dapat menampung air buangan yang dihasilkan. Berikut ini hasil analisis perhitungan dimensi pipa servis, pipa lateral, dan pipa induk masing-masing disajikan pada Tabel 8, Tabel 9, dan Tabel 10 berikut ini :

Tabel 8 Perhitungan Dimensi Pipa Servis

\begin{tabular}{|c|c|c|c|c|c|c|c|c|c|c|c|c|}
\hline $\begin{array}{l}\text { Nama } \\
\text { Pipa } \\
\text { (servis) }\end{array}$ & $\begin{array}{l}\Phi \text { pipa } \\
\text { (inchi) }\end{array}$ & $\begin{array}{c}A_{0} \\
\left(m^{2}\right)\end{array}$ & $\begin{array}{l}0_{0} \\
\text { (m) }\end{array}$ & $\begin{array}{l}R_{0} \\
\text { (m) }\end{array}$ & $n$ & $S_{0}$ & $\begin{array}{c}V \\
\text { (m/det) }\end{array}$ & $\begin{array}{l}Q \text { desain } \\
\left(\mathrm{m}^{3} / \text { det }\right)\end{array}$ & $\begin{array}{l}\text { Q rencana } \\
\text { (m³/det) }\end{array}$ & $\begin{array}{c}T \\
\text { (m) }\end{array}$ & $\begin{array}{l}h \\
\text { (m) }\end{array}$ & $\begin{array}{l}Y \\
\text { (m) }\end{array}$ \\
\hline $\mathrm{R} 1$ & 6 & 0,64 & 17 & 0,04 & 0,015 & 0,003 & 0,41 & 0,27 & 0,00031 & 0,14 & 0,05 & 0,11 \\
\hline $\mathrm{R} 2$ & 6 & 0,64 & 17 & 0,04 & 0,015 & 0,003 & 0,41 & 0,27 & 0,00031 & 0,14 & 0,05 & 0,11 \\
\hline R3 & 6 & 0,64 & 17 & 0,04 & 0,015 & 0,003 & 0,41 & 0,27 & 0,00011 & 0,14 & 0,05 & 0,11 \\
\hline
\end{tabular}


Tabel 8 Perhitungan Dimensi Pipa Servis (lanjutan)

\begin{tabular}{|c|c|c|c|c|c|c|c|c|c|c|c|c|}
\hline $\begin{array}{c}\text { Nama } \\
\text { Pipa } \\
\text { (servis) }\end{array}$ & $\begin{array}{l}\Phi \text { pipa } \\
\text { (inchi) }\end{array}$ & $\begin{array}{l}A_{0} \\
\left(m^{2}\right)\end{array}$ & $\begin{array}{l}O_{0} \\
\text { (m) }\end{array}$ & $\begin{array}{l}R_{0} \\
(m)\end{array}$ & $\mathbf{n}$ & $\mathrm{S}_{0}$ & $\begin{array}{c}V \\
\text { (m/det) }\end{array}$ & $\begin{array}{l}Q \text { desain } \\
\left(\mathrm{m}^{3} / \text { det }\right)\end{array}$ & $\begin{array}{l}\text { Q rencana } \\
\left(\mathrm{m}^{3} / \text { det }\right)\end{array}$ & $\begin{array}{c}T \\
(\mathrm{~m})\end{array}$ & $\begin{array}{c}\mathrm{h} \\
(\mathrm{m})\end{array}$ & $\begin{array}{c}Y \\
\text { (m) }\end{array}$ \\
\hline R4 & 6 & 0,64 & 17 & 0,04 & 0,015 & 0,003 & 0,41 & 0,27 & 0,00015 & 0,14 & 0,05 & 0,11 \\
\hline R5 & 6 & 0,64 & 17 & 0,04 & 0,015 & 0,003 & 0,41 & 0,27 & 0,00008 & 0,14 & 0,05 & 0,11 \\
\hline $\mathrm{R} 6$ & 6 & 0,64 & 17 & 0,04 & 0,015 & 0,003 & 0,41 & 0,27 & 0,00008 & 0,14 & 0,05 & 0,11 \\
\hline R7 & 6 & 0,64 & 17 & 0,04 & 0,015 & 0,003 & 0,41 & 0,27 & 0,00010 & 0,14 & 0,05 & 0,11 \\
\hline R8 & 6 & 0,64 & 17 & 0,04 & 0,015 & 0,003 & 0,41 & 0,27 & 0,00016 & 0,14 & 0,05 & 0,11 \\
\hline R9 & 6 & 0,64 & 17 & 0,04 & 0,015 & 0,003 & 0,41 & 0,27 & 0,00014 & 0,14 & 0,05 & 0,11 \\
\hline $\mathrm{R} 10$ & 6 & 0,64 & 17 & 0,04 & 0,015 & 0,003 & 0,41 & 0,27 & 0,00008 & 0,14 & 0,05 & 0,11 \\
\hline R11 & 6 & 0,64 & 17 & 0,04 & 0,015 & 0,003 & 0,41 & 0,27 & 0,00009 & 0,14 & 0,05 & 0,11 \\
\hline $\mathrm{R} 12$ & 6 & 0,64 & 17 & 0,04 & 0,015 & 0,003 & 0,41 & 0,27 & 0,00009 & 0,14 & 0,05 & 0,11 \\
\hline $\mathrm{R} 13$ & 6 & 0,64 & 17 & 0,04 & 0,015 & 0,003 & 0,41 & 0,27 & 0,00009 & 0,14 & 0,05 & 0,11 \\
\hline R14 & 6 & 0,64 & 17 & 0,04 & 0,015 & 0,003 & 0,41 & 0,27 & 0,00009 & 0,14 & 0,05 & 0,11 \\
\hline R15 & 6 & 0,64 & 17 & 0,04 & 0,015 & 0,003 & 0,41 & 0,27 & 0,00013 & 0,14 & 0,05 & 0,11 \\
\hline R14 & 6 & 0,64 & 17 & 0,04 & 0,015 & 0,003 & 0,41 & 0,27 & 0,00009 & 0,14 & 0,05 & 0,11 \\
\hline R15 & 6 & 0,64 & 17 & 0,04 & 0,015 & 0,003 & 0,41 & 0,27 & 0,00013 & 0,14 & 0,05 & 0,11 \\
\hline R16 & 6 & 0,64 & 17 & 0,04 & 0,015 & 0,003 & 0,41 & 0,27 & 0,00013 & 0,14 & 0,05 & 0,11 \\
\hline R17 & 6 & 0,64 & 17 & 0,04 & 0,015 & 0,003 & 0,41 & 0,27 & 0,00013 & 0,14 & 0,05 & 0,11 \\
\hline $\mathrm{R} 18$ & 6 & 0,64 & 17 & 0,04 & 0,015 & 0,003 & 0,41 & 0,27 & 0,00003 & 0,14 & 0,05 & 0,11 \\
\hline R19 & 6 & 0,64 & 17 & 0,04 & 0,015 & 0,003 & 0,41 & 0,27 & 0,00007 & 0,14 & 0,05 & 0,11 \\
\hline R20 & 6 & 0,64 & 17 & 0,04 & 0,015 & 0,003 & 0,41 & 0,27 & 0,00015 & 0,14 & 0,05 & 0,11 \\
\hline R21 & 6 & 0,64 & 17 & 0,04 & 0,015 & 0,003 & 0,41 & 0,27 & 0,02001 & 0,14 & 0,05 & 0,11 \\
\hline R22 & 6 & 0,64 & 17 & 0,04 & 0,015 & 0,003 & 0,41 & 0,27 & 0,00013 & 0,14 & 0,05 & 0,11 \\
\hline R23 & 6 & 0,64 & 17 & 0,04 & 0,015 & 0,003 & 0,41 & 0,27 & 0,00009 & 0,14 & 0,05 & 0,11 \\
\hline R24 & 6 & 0,64 & 17 & 0,04 & 0,015 & 0,003 & 0,41 & 0,27 & 0,00009 & 0,14 & 0,05 & 0,11 \\
\hline R25 & 6 & 0,64 & 17 & 0,04 & 0,015 & 0,003 & 0,41 & 0,27 & 0,00009 & 0,14 & 0,05 & 0,11 \\
\hline R26 & 6 & 0,64 & 17 & 0,04 & 0,015 & 0,003 & 0,41 & 0,27 & 0,00009 & 0,14 & 0,05 & 0,11 \\
\hline R27 & 6 & 0,64 & 17 & 0,04 & 0,015 & 0,003 & 0,41 & 0,27 & 0,00008 & 0,14 & 0,05 & 0,11 \\
\hline R28 & 6 & 0,64 & 17 & 0,04 & 0,015 & 0,003 & 0,41 & 0,27 & 0,00014 & 0,14 & 0,05 & 0,11 \\
\hline R29 & 6 & 0,64 & 17 & 0,04 & 0,015 & 0,003 & 0,41 & 0,27 & 0,00018 & 0,14 & 0,05 & 0,11 \\
\hline R30 & 6 & 0,64 & 17 & 0,04 & 0,015 & 0,003 & 0,41 & 0,27 & 0,00012 & 0,14 & 0,05 & 0,11 \\
\hline R31 & 6 & 0,64 & 17 & 0,04 & 0,015 & 0,003 & 0,41 & 0,27 & 0,00011 & 0,14 & 0,05 & 0,11 \\
\hline R32 & 6 & 0,64 & 17 & 0,04 & 0,015 & 0,003 & 0,41 & 0,27 & 0,00008 & 0,14 & 0,05 & 0,11 \\
\hline R33 & 6 & 0,64 & 17 & 0,04 & 0,015 & 0,003 & 0,41 & 0,27 & 0,00005 & 0,14 & 0,05 & 0,11 \\
\hline
\end{tabular}

Berdasarkan tabel 8 dimensi pipa servis yang terdiri dari 33 jalur pipa diperoleh debit rencana berkisar antara $0,00003 \mathrm{~m}^{3} /$ detik sampai $0,02001 \mathrm{~m}^{3} /$ detik. Hasil perhitungan debit desain lebih besar dari debit rencana dan kecepatan yang diperoleh melebihi kecepatan yang di izinkan yaitu 0,3 - 3 $\mathrm{m} /$ detik. 
Tabel 9 Perhitungan Dimensi Pipa Lateral

\begin{tabular}{|c|c|c|c|c|c|c|c|c|c|c|c|c|}
\hline $\begin{array}{c}\text { Nama } \\
\text { Pipa } \\
\text { (lateral) }\end{array}$ & $\begin{array}{l}\Phi \text { pipa } \\
\text { (inchi) }\end{array}$ & $\begin{array}{c}A_{0} \\
\left(m^{2}\right)\end{array}$ & $\begin{array}{l}O_{0} \\
(\mathrm{~m})\end{array}$ & $\begin{array}{l}R_{0} \\
(m)\end{array}$ & $\mathrm{n}$ & $\mathbf{s}_{0}$ & $\begin{array}{c}\mathrm{V} \\
\text { (m/det) }\end{array}$ & $\begin{array}{l}\text { Q desain } \\
\left(\mathrm{m}^{3} / \text { det }\right)\end{array}$ & $\begin{array}{c}\mathbf{Q} \\
\text { rencana } \\
\left(\mathrm{m}^{3} / \mathrm{det}\right)\end{array}$ & $\begin{array}{c}T \\
(\mathrm{~m})\end{array}$ & $\begin{array}{l}\mathrm{h} \\
\text { (m) }\end{array}$ & $\begin{array}{c}Y \\
\text { (m) }\end{array}$ \\
\hline S1 & 8 & 1,14 & 22,35 & 0,05 & 0,015 & 0,02 & 1,30 & 1,48 & 0,00061 & 0,191 & 0,06 & 0,14 \\
\hline S2 & 8 & 1,14 & 22,35 & 0,05 & 0,015 & 0,02 & 1,30 & 1,48 & 0,00026 & 0,191 & 0,06 & 0,14 \\
\hline S3 & 8 & 1,14 & 22,35 & 0,05 & 0,015 & 0,02 & 1,30 & 1,48 & 0,00017 & 0,191 & 0,06 & 0,14 \\
\hline S4 & 8 & 1,14 & 22,35 & 0,05 & 0,015 & 0,02 & 1,30 & 1,48 & 0,00026 & 0,191 & 0,06 & 0,14 \\
\hline S5 & 8 & 1,14 & 22,35 & 0,05 & 0,015 & 0,02 & 1,30 & 1,48 & 0,00023 & 0,191 & 0,06 & 0,14 \\
\hline S6 & 8 & 1,14 & 22,35 & 0,05 & 0,015 & 0,02 & 1,30 & 1,48 & 0,00018 & 0,191 & 0,06 & 0,14 \\
\hline S7 & 8 & 1,14 & 22,35 & 0,05 & 0,015 & 0,02 & 1,30 & 1,48 & 0,00026 & 0,191 & 0,06 & 0,14 \\
\hline S8 & 8 & 1,14 & 22,35 & 0,05 & 0,015 & 0,02 & 1,30 & 1,48 & 0,00031 & 0,191 & 0,06 & 0,14 \\
\hline 59 & 8 & 1,14 & 22,35 & 0,05 & 0,015 & 0,02 & 1,30 & 1,48 & 0,00023 & 0,191 & 0,06 & 0,14 \\
\hline S10 & 8 & 1,14 & 22,35 & 0,05 & 0,015 & 0,02 & 1,30 & 1,48 & 0,00015 & 0,191 & 0,06 & 0,14 \\
\hline S11 & 8 & 1,14 & 22,35 & 0,05 & 0,015 & 0,02 & 1,30 & 1,48 & 0,00009 & 0,191 & 0,06 & 0,14 \\
\hline S12 & 8 & 1,14 & 22,35 & 0,05 & 0,015 & 0,02 & 1,30 & 1,48 & 0,00009 & 0,191 & 0,06 & 0,14 \\
\hline $\mathrm{S} 13$ & 8 & 1,14 & 22,35 & 0,05 & 0,015 & 0,02 & 1,30 & 1,48 & 0,00031 & 0,191 & 0,06 & 0,14 \\
\hline S14 & 8 & 1,14 & 22,35 & 0,05 & 0,015 & 0,02 & 1,30 & 1,48 & 0,00018 & 0,191 & 0,06 & 0,14 \\
\hline S15 & 8 & 1,14 & 22,35 & 0,05 & 0,015 & 0,02 & 1,30 & 1,48 & 0,00018 & 0,191 & 0,06 & 0,14 \\
\hline S16 & 8 & 1,14 & 22,35 & 0,05 & 0,015 & 0,02 & 1,30 & 1,48 & 0,00023 & 0,191 & 0,06 & 0,14 \\
\hline S17 & 8 & 1,14 & 22,35 & 0,05 & 0,015 & 0,02 & 1,30 & 1,48 & 0,00029 & 0,191 & 0,06 & 0,14 \\
\hline S18 & 8 & 1,14 & 22,35 & 0,05 & 0,015 & 0,02 & 1,30 & 1,48 & 0,00018 & 0,191 & 0,06 & 0,14 \\
\hline S19 & 8 & 1,14 & 22,35 & 0,05 & 0,015 & 0,02 & 1,30 & 1,48 & 0,00005 & 0,191 & 0,06 & 0,14 \\
\hline
\end{tabular}

Berdasarkan tabel 9 dimensi pipa lateral yang terdiri dari 19 jalur pipa diperoleh debit rencana berkisar antara $0.00005 \mathrm{~m}^{3} /$ detik sampai $0.02016 \mathrm{~m}^{3} /$ detik. Hasil perhitungan debit desain lebih besar dari debit rencana dan kecepatan yang diperoleh melebihi kecepatan yang di izinkan yaitu 0,3 - 3 $\mathrm{m} /$ detik.

Tabel 10 Perhitungan Dimensi Pipa Induk

\begin{tabular}{|c|c|c|c|c|c|c|c|c|c|c|c|c|}
\hline $\begin{array}{c}\text { Jenis Pipa } \\
\text { (Induk) }\end{array}$ & $\begin{array}{c}\boldsymbol{\Phi} \text { pipa } \\
\text { (inchi) }\end{array}$ & $\begin{array}{c}\mathbf{A}_{\mathbf{0}} \\
\left(\mathbf{m}^{2}\right)\end{array}$ & $\begin{array}{c}\mathbf{O}_{\mathbf{0}} \\
\mathbf{( m )}\end{array}$ & $\begin{array}{c}\mathbf{R}_{\mathbf{0}} \\
(\mathbf{m})\end{array}$ & $\mathbf{n}$ & $\mathbf{S}_{\mathbf{0}}$ & $\begin{array}{c}\mathbf{V} \\
(\mathbf{m} / \text { det})\end{array}$ & $\begin{array}{c}\mathbf{Q} \text { desain } \\
\left(\mathbf{m}^{3} / \text { det}\right)\end{array}$ & $\begin{array}{c}\mathbf{Q} \\
\text { rencana } \\
\left(\mathbf{m}^{\mathbf{3}} / \text { det}\right)\end{array}$ & $\begin{array}{c}\mathbf{T} \\
(\mathbf{m})\end{array}$ & $\begin{array}{c}\mathbf{h} \\
(\mathbf{m})\end{array}$ & $\begin{array}{c}\mathbf{Y} \\
(\mathbf{m})\end{array}$ \\
\hline $\mathrm{T} 1$ & 8 & 1,14 & 22,35 & 0,05 & 0,015 & 0,02 & 1,30 & 1,48 & 0,00061 & 0,19 & 0,06 & 0,14 \\
$\mathrm{~T} 2$ & 8 & 1,14 & 22,35 & 0,05 & 0,015 & 0,02 & 1,30 & 1,48 & 0,00068 & 0,19 & 0,06 & 0,14 \\
$\mathrm{~T} 3$ & 8 & 1,14 & 22,35 & 0,05 & 0,015 & 0,02 & 1,30 & 1,48 & 0,00041 & 0,19 & 0,06 & 0,14 \\
$\mathrm{~T} 4$ & 8 & 1,14 & 22,35 & 0,05 & 0,015 & 0,02 & 1,30 & 1,48 & 0,00053 & 0,19 & 0,06 & 0,14 \\
$\mathrm{~T} 5$ & 8 & 1,14 & 22,35 & 0,05 & 0,015 & 0,02 & 1,30 & 1,48 & 0,02053 & 0,19 & 0,06 & 0,14 \\
$\mathrm{~T} 6$ & 8 & 1,14 & 22,35 & 0,05 & 0,015 & 0,02 & 1,30 & 1,48 & 0,00049 & 0,19 & 0,06 & 0,14 \\
$\mathrm{~T} 7$ & 8 & 1,14 & 22,35 & 0,05 & 0,015 & 0,02 & 1,30 & 1,48 & 0,00041 & 0,19 & 0,06 & 0,14 \\
$\mathrm{~T} 8$ & 8 & 1,14 & 22,35 & 0,05 & 0,015 & 0,02 & 1,30 & 1,48 & 0,00053 & 0,19 & 0,06 & 0,14 \\
\hline
\end{tabular}

Berdasarkan tabel 10 dimensi pipa induk yang terdiri dari 8 jalur pipa diperoleh debit rencana berkisar antara $0.00041 \mathrm{~m}^{3} /$ detik sampai $0.02053 \mathrm{~m}^{3} /$ detik. Hasil perhitungan debit desain lebih besar dari debit rencana dan kecepatan yang diperoleh melebihi kecepatan yang di izinkan yaitu 0,3 - 3 $\mathrm{m} /$ detik.

Kapasitas debit air limbah pada TPS 2 menuju ke IPAL 2 sebesar 0,00068 $\mathrm{m}^{3} /$ detik. Setelah ditentukaan ukuran diameter pipa yang akan digunakan, maka selanjutnya adalah menghitung mayor losses dan minor losses untuk mengetahui kehilangan tekanan pada pipa. 
a. Mayor Losses

Dengan diameter sebesar 0,152 m dapat dicari seberapa besar head losse (mayor losses) yang terjadi. Perhitungan dapat dilihat sebagai berikut :

$$
\mathrm{Hf}=? \frac{\mathrm{Q}}{0,2785 \times \mathrm{CxD}^{2,63}} ?^{1,85} \times \mathrm{L}
$$

Maka didapatkan hasil hf sebesar $0,0036 \mathrm{~m}$

b. M inor Losses

$$
\mathrm{Hc}=\mathrm{Kc} \frac{\mathrm{v}_{2}{ }^{2}}{2 \mathrm{~g}}
$$

Maka didapatkan hasil Hc sebesar $0,0001 \mathrm{~m} / \mathrm{s}$

c. Perhitungan tekanan yang diperlukan sebagai berikut :

$H_{\text {req }}=5,26 m+0,0036 \mathrm{~m}(0,00068 / 0,0001)=26,32 \mathrm{~m}$

Perhitungan daya pompa dihitung denganmenggunakan rumus sebagai berikut :

$$
P=\frac{? \times ? \times ? \times ?}{75}
$$

Maka didapatkan hasil daya pompa sebesar 2,35 kW

\section{Kesimpulan}

Dari hasil perencanaan dan analisa yang telah dilakukan, dapat disimpulkan bahwa sistem penyaluran air buangan Perumahan Grand Sukati dibuat dengan sistem terpisah, dimana :

a. Saluran drainase air hujan direncanakan dengan sistem terbuka secara gravitasi dimana penampang saluran berbentuk segiempat dengan dimensi saluran primer untuk lebar saluran sebesar 1,50 $\mathrm{m}$ dan kedalaman saluran sebesar 0,75 $\mathrm{m}$ dan saluran sekunder untuk untuk lebar saluran sebesar 0,74 m dan kedalaman sebesar 0,37 m.

b. Saluran air limbah direncanakan dengan sistem perpipaan secara gravitasi dan pompa dengan bahan pipa PVC menggunakan pipa berdiameter 4" untuk pipa persil, pipa berdiameter 6" untuk pipa servis, pipa berdiameter 8" untuk pipa lateral, dan pipa berdiameter 8" untuk pipa induk.

\section{Pustaka}

Badan Meteorologi Klimatologi dan Geofisika Supadio. 2012. Data Curah Hujan 2002-2011. Pontianak: BMKG.

Chow, Van Te., dan E.V. Nensi Rosalina. 1997. Hidrolika Saluran terbuka. Jakarta: Erlangga.

Dinas Pekerjaan Umum. 2008. M ateri Pengolahan Air Limbah. Pontianak: Dinas Pekerjaan Umum. Linsley, Ray K., dan Joseph B. Franzini. 1996. Teknik Sumber Daya Air Jilid 2. Jakarta: Erlangga. Pergub DKI Jakarta. 2005. Lampiran Pergub DKI Jakarta No.122. Jakarta: Pergub DKI. Soewarno, 1995. Hidrologi Aplikasi M etode Statistik untuk Analisa Data. Jilid 1. Bandung: Nova. Soewarno,1995. Hidrologi Aplikasi M etode Statistik untuk Analisa Data. Jilid 2. Bandung: Nova. Sri Harto Br., 1981. M engenal Dasar Hidrologi Terapan. Yogyakarta: Keluarga M ahasiswa Teknik sipil. Suripin, 2004. Sistem Drainase Perkotaan yang Berkelanjutan. Yogyakarta: Andi Offset. Undang-Undang Republik Indonesia Nomor 28 Tahun 2002. Tentang Bangunan Gedung.

Wesli, 2008. Drainase Perkotaan. Yogyakarta: Graha Ilmu. 